the oval window, or the vestibular nerve may be cut. Tetraethyl-ammonium chloride is used to reduce high blood pressure but, so far as the writer knows, has no place in the diagnosis and treatment of Ménière's syndrome.

\section{Sprue and Malignant Disease}

Q.-Does sprue predispose to malignant disease? If a patient with sprue developed a carcinoma of the bowel laparotomy could not be undertaken because of the weakness and emaciation, and death might be wrongly attributed to the sprue.

A.-There is no reliable evidence that sprue predisposes to malignant disease. With adequate treatment most cases of sprue respond rapidly and satisfactorily enough to permit exploratory operation where indicated.

\section{Gonorrhoea, Syphilis, and Penicillin}

Q.-A patient who was successfully treated with penicillin for gonorrhoea four months ago has developed a primary sore in which Spirochaeta pallida has been found. The Wassermann reaction is negative. (a) What is the prognosis in these cases? Does the fact that penicillin has been given make cure more difficult? (b) The patient had unprotected intercourse with his wife about a month before the first sign of the sore, but not after that. Is there any danger that she might have been infected on this occasion, which was presumably during the incubation period?

A.- (a) The prognosis is good provided adequate treatment is administered without delay. There is no reason to suppose that the syphilis will be more difficult to cure because the patient was treated with penicillin for gonorrhoea. (b) There is a risk that the patient may have infected his wife, but it is small; it would therefore be wise to keep her under observation for at least three months, with periodical clinical and serological examinations.

\section{Retardation of Growth}

Q.-(a) Has an anti-growth hormone definitely been isolated? (b) What is the substance that might be called the opposite number of the anterior pituitary growth hormone? (c) Can such substance be utilized to prevent the growth of cells in certain organs of the human body to the exclusion of cells in other organs of the body?

A.-(a) No. (b) There is no such substance, but experimentally the giving of certain hormones, such as oestrogens, will inhibit initial secretion of the pituitary gonadotrophic hormone and subsequently all other hormones, including the growth hormone. Thus Zondek produced dwarfism in mice so treated, together with hypogonadism, and the pituitary gland showed loss of the granules of both the eosinophil and the basophil cells, and sometimes a large chromophobe adenoma was also produced. Clinically it is difficult to stop somatic growth or to inhibit the development of acromegaly by such methods, but relative success in the latter is sometimes obtained. (c) No.

\section{Keeping Qualities of Aspirin}

Q.-Does aspirin in a mixture deteriorate appreciably? Is it best to prescribe aspirin in tablet form?

A.- Aspirin is a somewhat unstable chemical, hydrolysing in the presence of water into free salicylic and acetic acids. In mixture form it decomposes fairly rapidly, and even in powder and tablet form it cannot be relied upon to keep for prolonged periods, particularly in a moist atmosphere. The odour of acetic acid on opening the container is an indication of decomposition, and if this odour is strong one may suspect very appreciable deterioration.

\section{Acute Cystitis}

Q. - What is the prognosis in a man of 70 with some prostatic enlargement who had an acute cystitis twelve years ago and a recurrence two months ago? The urine was freed from the infecting organisms-Bact. coli and Str. faecalis-after a course of sulphadiazine. Can treatment with sulphonamides be continued with impunity, and are further relapses likely?

A.- It is very difficult to get rid of a urinary infection in the presence of residual urine, and in this case there is likely to be residual urine. The best method of treatment is either by means of calcium mandelate or by the use of the sulphonamides. As a sterile urine was temporarily obtained after taking sulphadiazine there is no reason why this should not be repeated. Sulphamezathine is probably even less toxic than sulphadiazine, but if either of these preparations is taken in moderate doses and with plenty of fluids for only a week no harm will be done. Occasional relapses are likely, but in time a higher resistance to the infecting organisms may be developed. Provided the residual urine does not increase, the outlook is satisfactory.

\section{Nerve Deafness and Syphilis}

Q.-What is the best treatment for a patient aged 65 with marked arteriosclerosis of the limbs who is now rapidly developing nerve deafness? He has positive Wassermann and Kahn reactions and has had a full course of penicillin without effect, but no other antispecific treatment. The old specific trouble has been quiescent for years apparently, and the positive Wassermann reaction was only accidentally discovered. Would tryparsamide and bismuth arrest the nerve deafness?

A. - It would be wise to obtain the opinion of a neurologist 'on whether the nerve deafness is due to syphilis, which seems at least problematical. The full effects of penicillin in certain forms of syphilis are often not apparent for some months. Assuming the patient has had at least five mega units, further antispecific treatment is not indicated until several months have elapsed. If the condition has not improved by then, injections of oil-soluble bismuth, given twice weekly, might be worth trying. Tryparsamide should not be employed. In view of the condition and age of the patient the prognosis is far from good.

\section{NOTES AND COMMENTS}

Loss of Weight after Hysterectomy.-Dr. A. Russell (Edinburgh) writes: I trust you will permit a suggestion concerning the answer to the query describing loss of weight after hysterectomy ("Any Questions?" July 10, p. 117). The slowly progressive loss of weight with wasting apparently confined to face, upper limbs, and trunk-the lower limbs remaining "quite muscular"-might well suggest a progressive lipodystrophy. You will agree that this condition may arise in adult life, principally in females, and may be associated with atrophic lesions of the hypophysis, ovarian lesions, etc., so that the pathology implied in the question may not be unrelated. The concentration of the wasting in the face, together with the unimpaired general condition, would appear to give added support to the diagnosis suggested.

\section{Corrections}

In our report of a meeting of the combined Sections of Child Health and Radiology on Friday, July 2 (Journal, July 17, p. 162), Professor Wilfrid Gaisford (Manchester) was reported as saying." not all malignant cases were curable." This should have read " not all cases were fatal, which is quite commonly assumed." The reference to a raised basal metabolic rate in cases of medulloblastoma was also incorrect and should have read: "Topper had found that in all intracranial tumours, whether benign or malignant, the basal metabolic rate was lowered, whereas in all malignant tumours in other parts of the body it was raised." The phrase "staggering was a common first symptom " should have been deleted, and Wilms's tumours are, of course, radiosensitive. "The inguinal glands were enlarged ..." should have read "were not enlarged."

We regret that in the letter from Sir Frederick Menzies (July 17, p. 171) an error occurred in the printing of the first line of the second paragraph. It should read: "Not one of these men ever received any public recognition of their great services to London. .

There was a misprint in the report of the visit of the Section of Pathology to the Strangeways Research Laboratory at Cambridge (July 17, p. 160). Reference was made to an important demonstration of the histological assessment of the radiation treatment of cancer by "Dr. A. Glausmann and Dr. F. G. Spears." This should have read "Dr. A. Glucksmann."

All communications with regard to editorial business should be addressed to THE EDITOR, BRITISH MEDICAL JOURNAL, B.M.A. HOUSE, TAVISTOCK SQUARE, LONDON, W.C.1. TElEPHONE: EUSTON 2111. TElegrams: Aitiology, DRIGINAL ARTICLES AND LETTERS forwarded fo publication are understood to be offered to the British Medical Journal alone. Authors desiring REPRINTS should communicate with the Publishing Manager, B.M.A. House, Tavistock Square, W.C.1, on receipt of proofs

D. Advertisement Manager. B.M.A. House, Tavistock Square, London, W.C.1 (hours 9 a.m. to 5 p.m.). TELEPHONE: EUSTON 2111. TELEGRAMS: Britmedads, Westcent, London. MEMB SUBSCRIPTIN should be sent to the SECRETARY of the Association. EUSTON 2111. Telegrams : Medisecra, Westcent, London.
B.M.A. ScotrisH OFFICE: 7 , Drumsheugh Gardens, Edinburgh. 